\title{
ACHPA: A sensor based system for automatic environmental control in hydroponics
}

\author{
Asif SIDDIQ ${ }^{1}$, Muhammad Owais TARIQ ${ }^{1 *}$ (D), Anum ZEHRA², Salman MALIK ${ }^{1}$
}

\begin{abstract}
The trend towards tunnel farming and hydroponic systems is increasing owing to the climatic changes as well as the need to increase crop yield. Hydroponic is a technique of growing plants without soil. Tunnel farming and hydroponic system requires controlled environmental parameters like temperature, humidity and soil moisture for better production of crops. This paper presents an effective method, named, ACHPA (Automatically Controlled Hydro-Ponic Agriculture) scheme that monitor and controls environmental parameters using sensors and controller. ACHPA provides better environmental control over traditional manual monitoring and controlling, thus yield high-quality crops. Sensor based monitoring and control system regulates the temperature and humidity of the tunnel to yield better. For the sake of saving water, an efficient method of drip irrigation is implemented which delivers water directly to the plants rather than being sprayed on as in conventional farming method. The proposed system here is tested for controlled environment and observations recorded for crop analysis purpose. This makes an effective solution to growing highly efficient, good quality and disease free crop production.
\end{abstract}

Keywords: hydroponics; environmental control; sensors; controller; yield.

Practical Application: Automated hydroponics and tunnel farming.

\section{Introduction}

Agriculture has been one of the primary occupations of man since early civilization. Agriculture plays an important role in development of economy of nations and is considered as an essential part of human life cycle (Nalwade \& Mote, 2017). In recent years, the world has faced a drastic change in climate resulting in increased environmental stresses like untimely floods, change in seasonal temperatures and wind dispatches. These changes have affected the field of agriculture with decreased production and crops quality. By 2050 world population is estimated to be 9 billions thereby increasing food necessity by $70 \%$ (Collado et al., 2018). One of the mechanisms used by the food industry to overcome this shortfall in the yield is the use of tunnel farming/hydroponics agriculture where environmental parameters like temperature, humidity and soil moisture are controlled. Controlled environment production involves more sophisticated growing techniques than unprotected cultivation in the field (Saha, 2017). The results from the Design Expert software showed height of the plants growing faster in hydroponic system as compared too traditional soil system (Gashgari et al., 2018).

Funding agencies like SMEDA and USAID have undertaken some experimental research on watermelon, apples, muskmelon, tomato and cucumber cultivation using tunnel farming. The results vary from country to country, but have shown expansion in growth in most of the cases. Food industries are undergoing technological transitions due to increase in worldwide population and unavailability of low cost fertile land. These transitions include tunnel farming for off-season as well as pre-season growth, vertical farming for big cities and home kitchen gardening to complete the individual needs.
Soil is the most accessible and widely used medium for crop production because it transfers supplements i.e. water efficiently and docks for development, but large use of pesticides in harvests brought poor fruitfulness in the soil. Hydroponics is the technique of growing plants without soil (Siddiqi, 2002). Roots submerged in hydroponic solution (Matos et al., 2015), with or without using dormant medium like Rockwool and coconut fiber (Mohanraj I, 2016), receives a balanced nutrition, essential for plant growth and development (Hirofumi Ibayash et al., 2016).

For many years, hydroponic system was manually controlled which resulted in low crop productivity due to inefficient method and improper control of environmental parameters. Then automated tunnel farming/hydroponics was introduced to overcome the problems occurred by manual control.

ACHPA controls environmental parameters i.e. temperature, humidity and soil moisture using sensors placed at convenient distances and a centralized controller to achieve a controlled environment for the production of crops. The operational ranges of the environmental parameters to be controlled are pre-fed in the controller. Environmental parameters received from the sensors are than compared with the pre-fed values for controlling action. Results strongly suggest using ACHPA controls environmental parameter in better way resulting in increased crop yield.

Environmental parameters i.e. temperature, humidity, soil moisture, and light directly influences the production of plants. These parameters are mostly responsible for the development of plants and play an important role in quality and productivity.

${ }^{1}$ Department of Electrical Engineering, Pakistan Institute of Engineering and Technology, Multan, Pakistan

${ }^{2}$ Department of Basic Sciences, Pakistan Institute of Engineering and Technology, Multan, Pakistan

*Corresponding author: engr.mot@gmail.com 
Temperature influences plant development process like transpiration, respiration, and flowering. Humidity controls moisture loss of the plant because a decrease in transpiration rate is directly proportional to the amount of humidity in the air (Asolkar \& Bhadade, 2015). Soil moisture is essential for the growth of plants because plants receive water and nutrients by roots and lose water by transpiration process. Plants manufacture glucose through the process of photosynthesis, which requires energy, which is directly captured from light (Asolkar \& Bhadade, 2015).

In conventional tunnel farming method, the farmer has to go to farm regularly to check and measure environmental parameters (Kumar \& Cho, 2014), which require an enormous amount of hard work and attention, some negligence, can also result in poor quality and low productivity (Asolkar \& Bhadade, 2015). Automated controlled tunnel farming and hydroponic system help to overcome the problems occurred by manual control and traditional farming. Controlled environment agriculture (CEA) supplements crop production and quality by protecting the crops from pest, diseases and maintaining growing conditions (Niu \& Masabni, 2018).

Hydroponics plants have various types of planting media such as Rockwell, sponge, coconut and other coconut powder (Sihombing et al., 2017), (Velazquez et al., 2013). The key benefits of hydroponic technology include water reusability and low plant damage due to controlled pesticide use (Mr \& Kulkarni, 2017). Further drip irrigation technique supplies small water to the roots of plants, which ultimately save a lot of water (Rammurthy, 2010), (Singh \& Bansal, 2011), (Aniket Hade \& Sengupta, 2014). Water is supplied frequently, often daily, to maintain soil moisture condition with proper use of water resources (Shweta Bopshetty, 2017), (Sales et al., 2015). Drip irrigation system makes the proficient use of water because water is directly fed to the roots of plants with no or low losses (Agrawal \& Singhal, 2015), (Hussain et al., 2013).

Due to the issues in manual hydroponics, automated controlled hydroponics has been discussed in many papers and remains an open field of research.

(Asolkar \& Bhadade, 2015) gave an effective method of controlling the greenhouse and crop monitoring using GSM, proposing an effective method to replace traditional farming. (Nishimura et al., 2018) provided a high accuracy and low-cost sensor module to measure temperature and nutrition level. Only for a remote control area, which is difficult to establish. (Adhau et al., 2017) worked on designing a fully automated low cast hydroponic system in which a self-controlled automated system was developed to import real-time data using AVR microcontroller. According to him, the progress in hydroponics by only using on-off controller is sufficient, in this regard PID controller not required. (Dania et al., 2015) provided an Arduino-based nutrition feeding automation system for scaled nutrient film technique, aims to provide water and nutrients delivery automatically to the roots of plants. However, such direct water supply to the roots creates water loss problem, drip irrigation gives much better results to save water. (Burchi et al., 2018) designed a high technology greenhouse to manage a controlled environment in an efficient way for different crops. The system was equipped with sensors and monitoring system.
However, the project was only for small scale and not tested for large scale. (Saraswathi et al., 2018) worked on automation of greenhouse hydroponic system and maintenance of $\mathrm{PH}$ and electric conductivity in the hydroponic system. This is also implemented only for the small scale.

Controller design is a major topic in automatic technologies. On off controller, PID or combinations of these terms (P, PI, and PD) are most commonly used in industrial position control, robotics and motor drive (Jahanshahi, 2015), (Ponce et al., 2015), (Reyes \& Rosado, 2005), (Sondhi \& Hote, 2014), (Jingzhuo et al., 2014), (Can \& Ozguven, 2017). PID controllers (Ziegler \& Nichols, 1940), (Haglund, 1988, 1995) are widely used in industrial control systems because PID controllers have the capacity to eliminate the steady-state error of signals (Matos, 2002). PID controller supplies smooth control action, numeric output and makes the system stable (Adhau et al., 2017).

A thorough review of the above work shows there are only a few studies concerning monitoring and controlling of tunnel farming and hydroponic unit. Above discussion described implementation of the control unit in a remote area only, expensive method of controlling using PID controller implemented only in a small scale and water losses using simple water supply to the crops. The current paper considers these problems and proposes an efficient approach to monitoring and controlling mechanism for completely automated hydroponic system.

This paper comprises of following sections: Section 2 explains the materials and methodology of the proposed system. Section 3 explains the analysis and experimental results. Section 4 summarizes the results and conclusion generated by the proposed system.

\section{Materials and methods}

This section explains the methods and processes used in system development as shown in Figure 1. It completes in four stages, stage 1: data analysis, stage 2: controller command, stage 3 : system implementation and stage 4 : rechecking of previously stored data

The first stage in system development is the identification of the system requirements. At this stage, sensor data is analyzed namely DHT11 (temperature and humidity sensor). Then these values are sent to the controller for processing.

In the second stage, the controller reads data sent by sensors and commands to the actuator to maintain a controlled climate for the crops. In stage 3 , to overcome the effects of high temperature, proper ventilation is required so the fans are turned

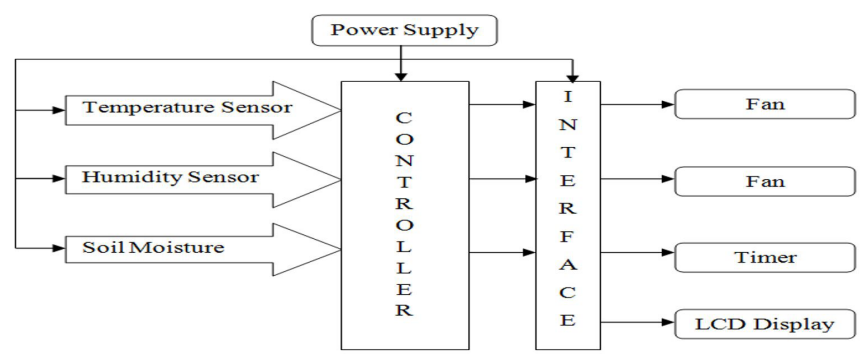

Figure 1. Block Diagram. 
$\mathrm{ON}$ and after regulating the temperature; they are commanded to be turned OFF. In addition, for maintain the adequate water moisture for the roots; water pumps of drip irrigation system are regulated upon readings received from moisture sensors.

Data collected by the sensors is stored to evaluate growth with regulated climate conditions. It will allow the stakeholder to continuously monitor the cultivation system. A basic chart of the process is shown in Figure 2 below.

To better understand the working of the system, assume that the fans are initially off and the temperature of the tunnel increases than the preset threshold value i.e. more than $40^{\circ} \mathrm{C}$. The controller after checking the present state of the fans $(\mathrm{F}=0)$ will switch on the fans changing the status as $\mathrm{F}=1$. The controller will recheck the temperature value after every 2 minutes. If $\mathrm{F}=1$ and temperature is greater than $37^{\circ} \mathrm{C}$, the controller will do nothing and the fan will remain $\mathrm{ON}$. If $\mathrm{F}=1$ and the temperature becomes equal to or less than $37^{\circ} \mathrm{C}$, the controller will turn off the fan making $\mathrm{F}=0$ in the software variable $\mathrm{F}$. The procedure gives a range of $3^{\circ} \mathrm{C}$ for $\mathrm{ON}-\mathrm{OFF}$ control. A similar procedure is adopted for humidity control with variable $\mathrm{H}$ in the software. In case temperature and humidity variables are competing, temperature is given priority over humidity since temperature plays more vital role in crop yield than humidity. Moisture is controlled using a timer. As soon as the moisture is sensed below 96\%, pumps start supplying water for three minutes. LCD display attached shows all current values of temperature, humidity and soil moisture.

\section{Results and discussion}

In this paper, a system is designed to check and compare the difference of the manually controlled tunnel farm with automatically controlled tunnel farm for the regulated and varied values of temperature and humidity. Monitoring values of manually controlled farm are taken after every thirty minutes and automatically controlled farm values are programmed to be read after every two minutes. Values of temperature and humidity have been taken 8 hours per day (day light), at different atmospheric temperatures on different days. The results are simulated using MATLAB. Threshold values of temperature and humidity are described below.

The threshold value of temperature $=37$ to $40{ }^{\circ} \mathrm{C}$

The threshold value of humidity $=55$ to $60 \%$

Day 1

Table 1 shows the data of day 1 with temperature Range of 33 to $43{ }^{\circ} \mathrm{C}$ and behavior graph is shown in Figure 3 and Figure 4 .

Day 2

Table 2 shows the data of day 2 with temperature Range of 30 to $35^{\circ} \mathrm{C}$ and behavior graph is shown in Figure 5 and Figure 6 .

Day 3

Table 3 shows the data of day 3 with temperature Range of 34 to $42^{\circ} \mathrm{C}$ and behavior graph is shown in Figure 7 and Figure 8 .

Day 4

Table 4 shows the data of day 4 with temperature Range of 35 to $45^{\circ} \mathrm{C}$ and behavior graph is shown in Figure 9 and Figure 10.

Table 1. Average of Field Observation (Day 1).

\begin{tabular}{lcccc}
\hline \multicolumn{5}{c}{ Day 1 } \\
\hline \multicolumn{1}{c}{ Parameters } & Min & Max & Median & SD \\
\hline Temperature $\left({ }^{\circ} \mathrm{C}\right)$ & 33 & 43 & 38 & 4.5 \\
Humidity (\%) & 55 & 63 & 58.5 & 3.53 \\
Soil Moisture (\%) & 95 & 100 & 97.5 & 2.06 \\
Time (hr.) & 0 & 8 & 4 & 3.53 \\
Distance (ft.) & 0 & 150 & 75 & 74.5 \\
\hline
\end{tabular}

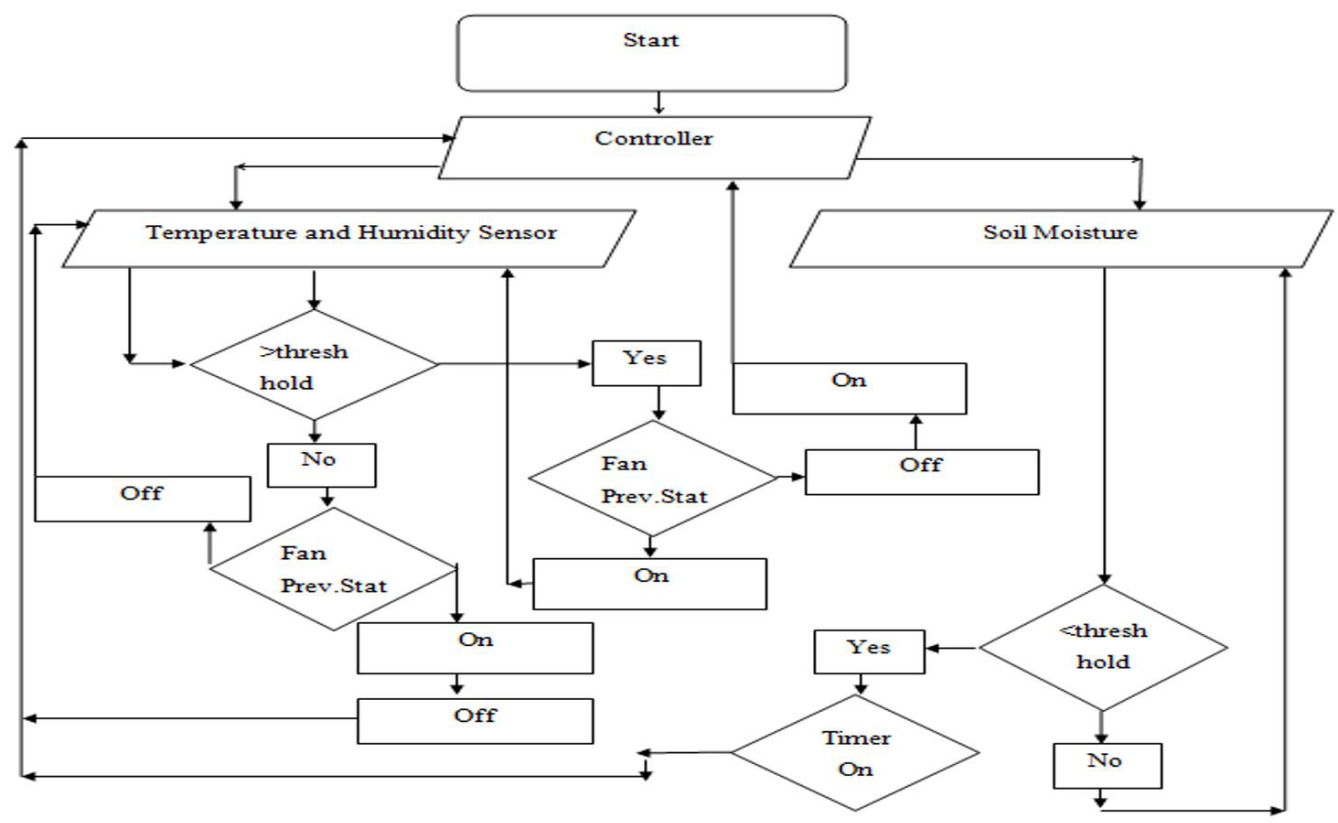

Figure 2. Flow Chart for System Design Process. 


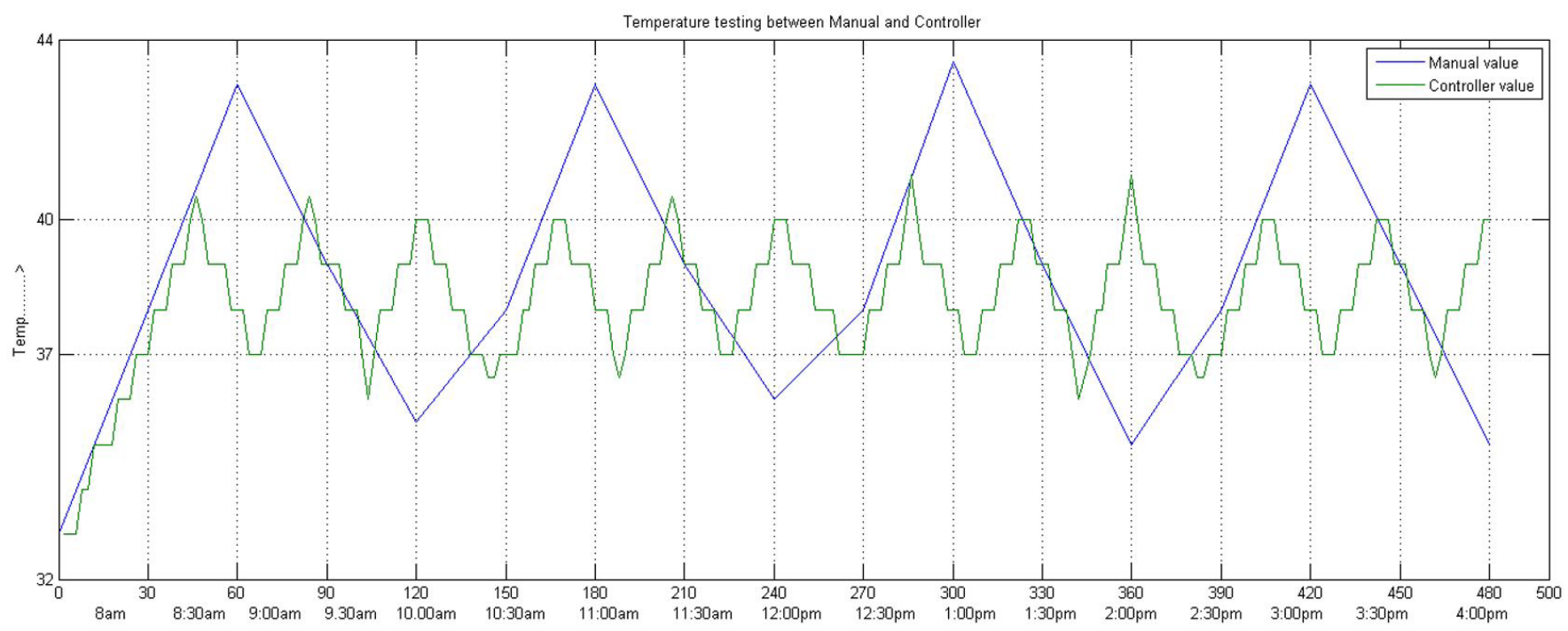

Figure 3. Time vs. Temperature (Day 1).

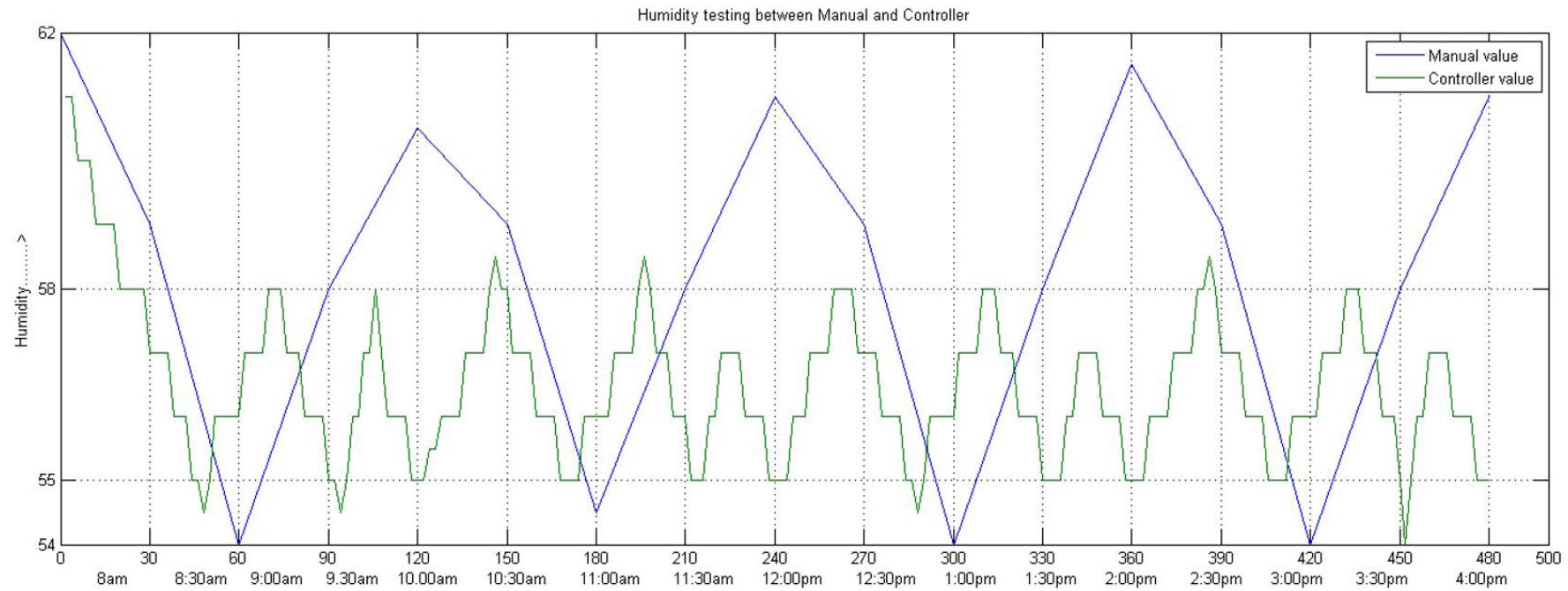

Figure 4. Time vs. Humidity (Day 1).

Table 2. Average of Field Observation (Day 2).

\begin{tabular}{lcccc}
\hline \multicolumn{5}{c}{ Day 2 } \\
\multicolumn{1}{c}{ Parameters } & Min & Max & Median & SD \\
\hline Temperature $\left({ }^{\circ} \mathrm{C}\right)$ & 30 & 35 & 32.5 & 2.06 \\
Humidity $(\%)$ & 55 & 63 & 58.5 & 3.53 \\
Soil Moisture $(\%)$ & 96 & 100 & 98 & 1.58 \\
Time (hr.) & 0 & 8 & 4 & 3.53 \\
Distance (ft.) & 0 & 150 & 75 & 74.5 \\
\hline
\end{tabular}

Table 3. Average of Field Observation (Day 3).

\begin{tabular}{lcccc}
\hline \multicolumn{5}{c}{ Day 3} \\
\multicolumn{1}{c}{ Parameters } & Min & Max & Median & SD \\
\hline Temperature $\left({ }^{\circ} \mathrm{C}\right)$ & 34 & 42 & 38 & 3.53 \\
Humidity $(\%)$ & 53 & 63 & 57.5 & 4.52 \\
Soil Moisture $(\%)$ & 95 & 100 & 97.5 & 2.06 \\
Time (hr.) & 0 & 8 & 4 & 3.53 \\
Distance (ft.) & 0 & 150 & 75 & 74.5 \\
\hline
\end{tabular}

Day 5

Table 5 shows the data of day 5 with temperature Range of 33 to $43{ }^{\circ} \mathrm{C}$ and behavior graph is shown in Figure 11 and Figure 12.

Day 6

Table 6 shows the data of day 6 with temperature Range of 33 to $43{ }^{\circ} \mathrm{C}$ and behavior graph is shown in Figure 13 and Figure 14.

In the graphs, there are different values of temperature and humidity at different days and time. After the comparison between manual and controller values, it is concluded that in manual control, values of environmental parameters varies largely and is summarized in Table 7. This variation in temperature or humidity in manual control creates a problem to maintain the required condition of environment for crops thereby affecting the quality and yield. 
Siddiq et al.

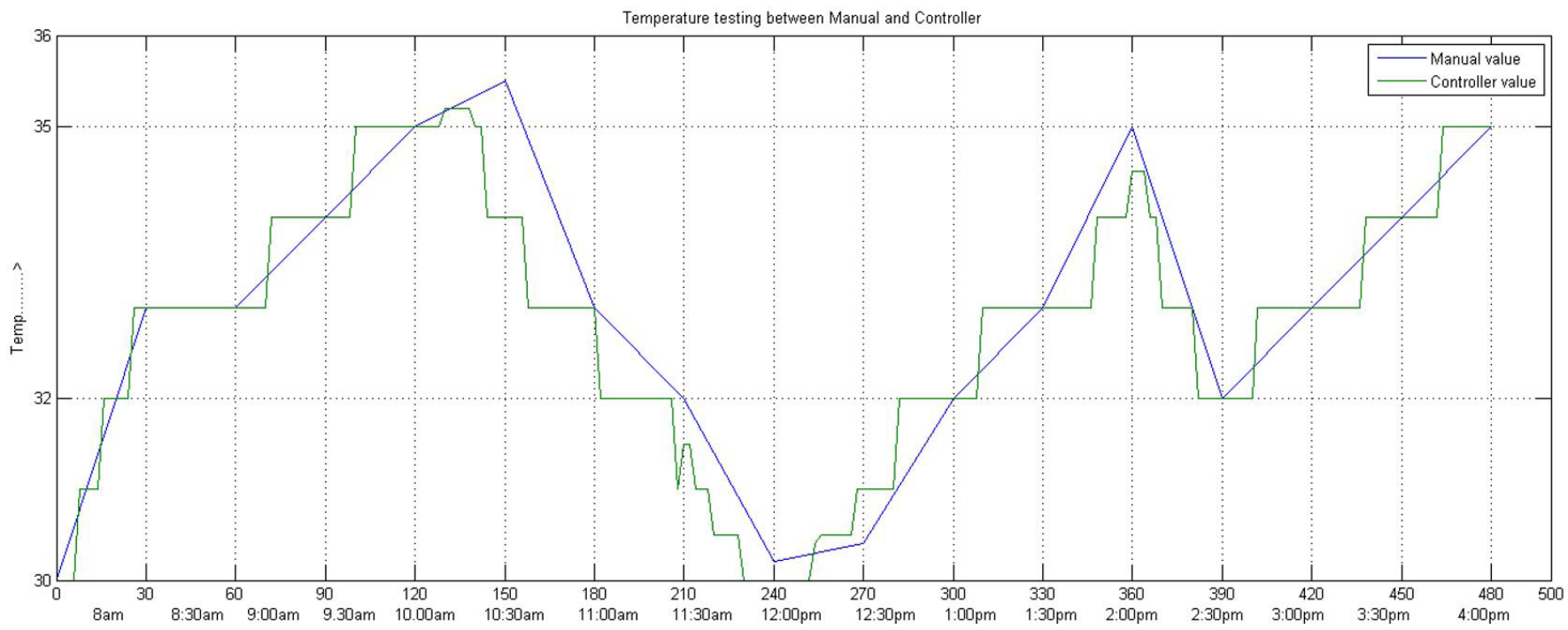

Figure 5. Time vs. Temperature (Day 2).

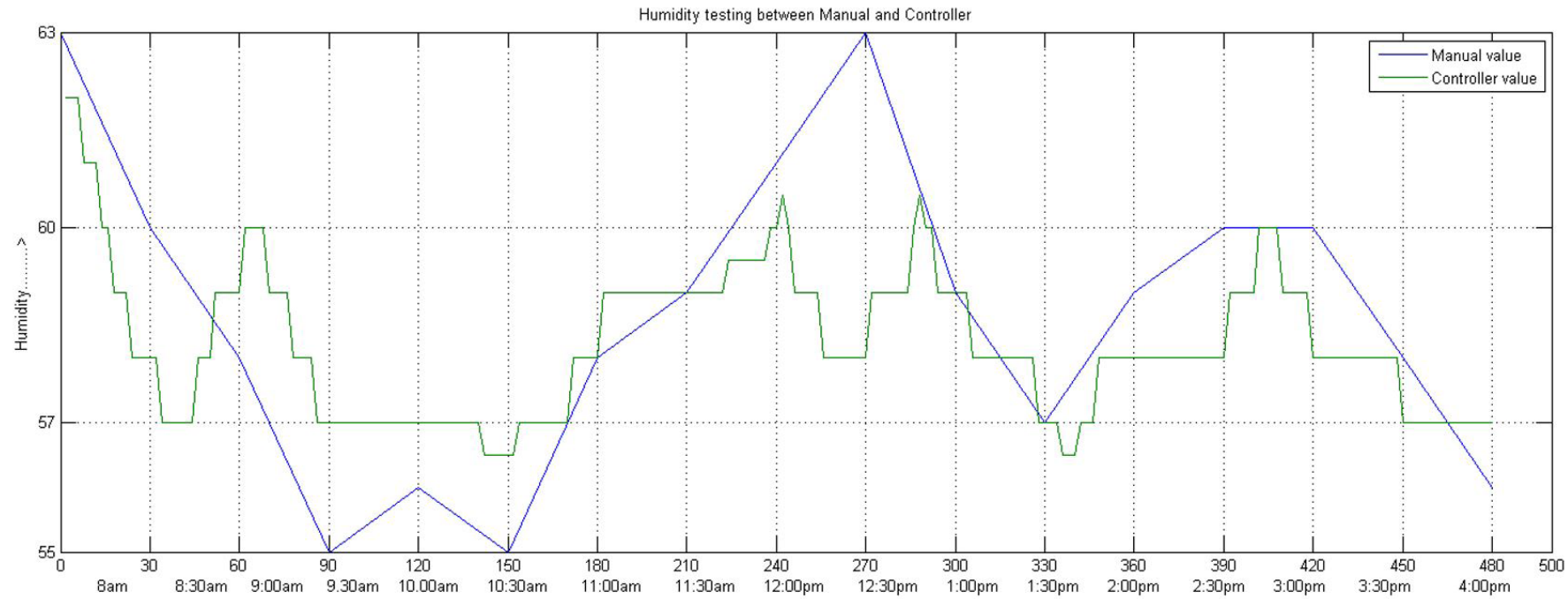

Figure 6. Time vs. Humidity (Day 2).

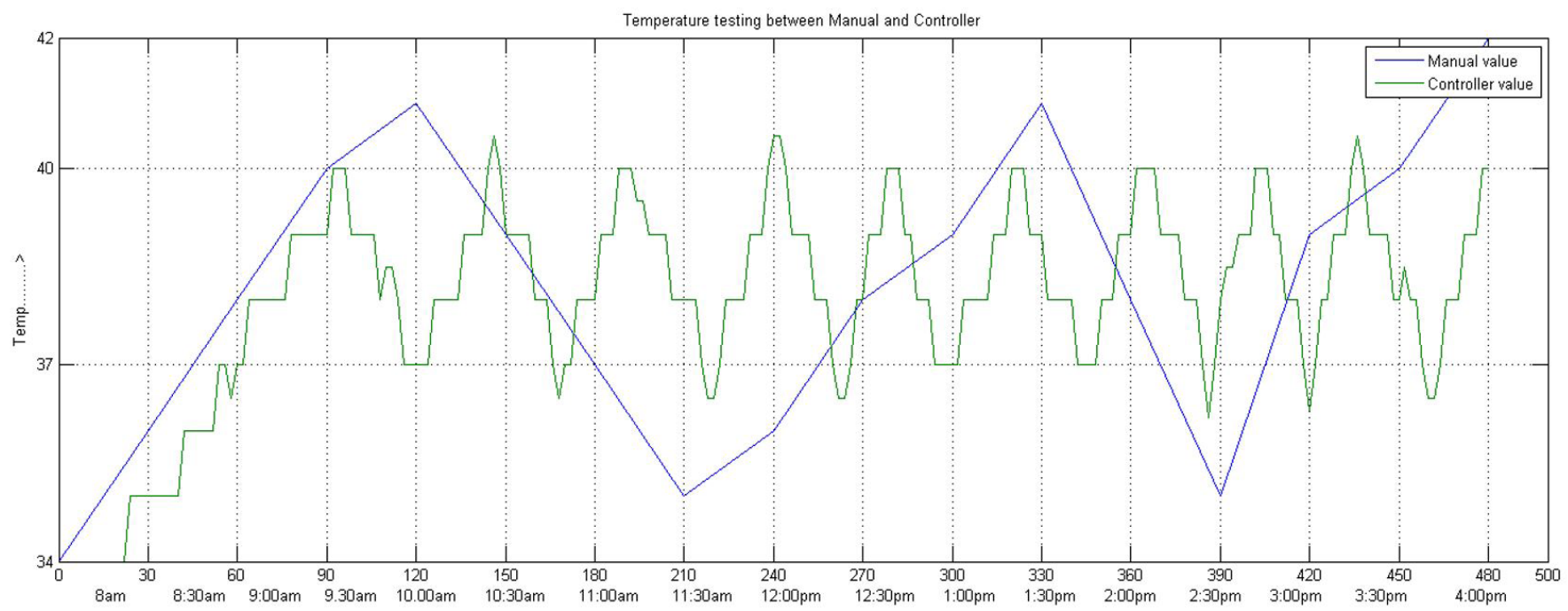

Figure 7. Time vs. Temperature (Day 3). 


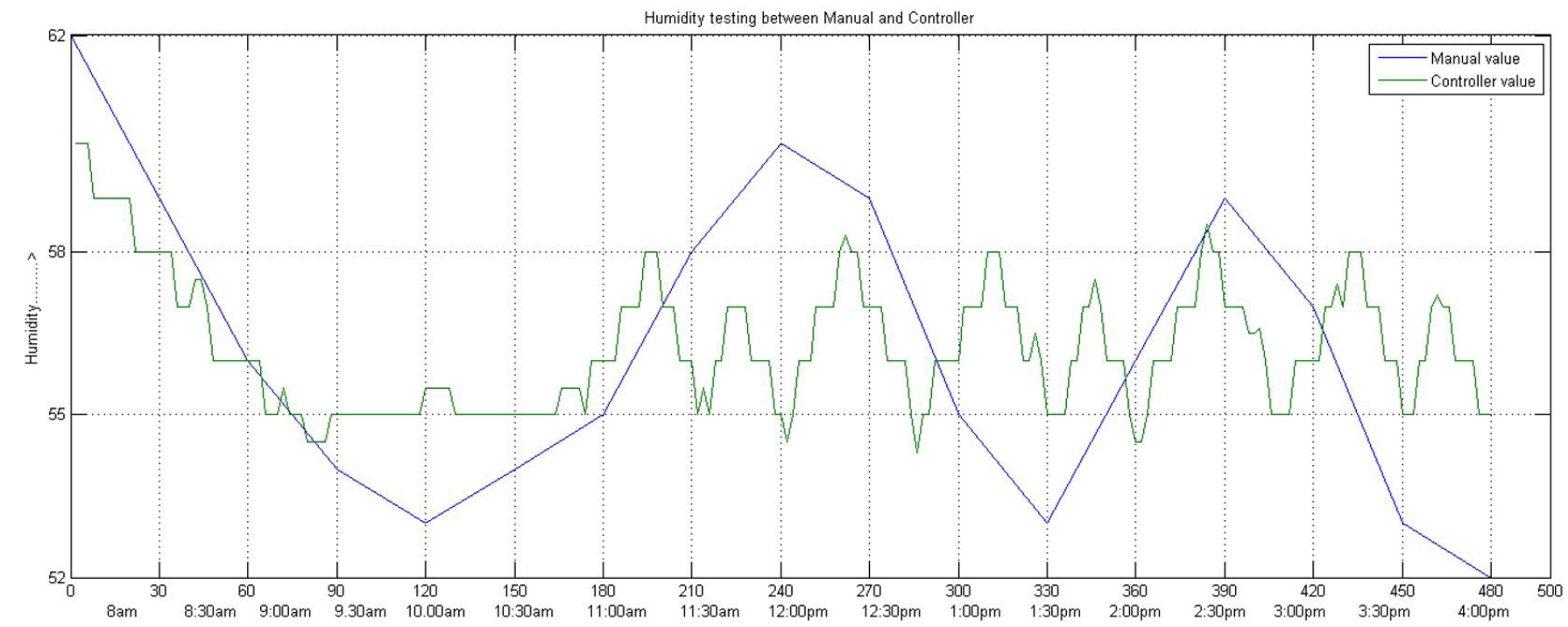

Figure 8. Time vs. Humidity (Day 3).

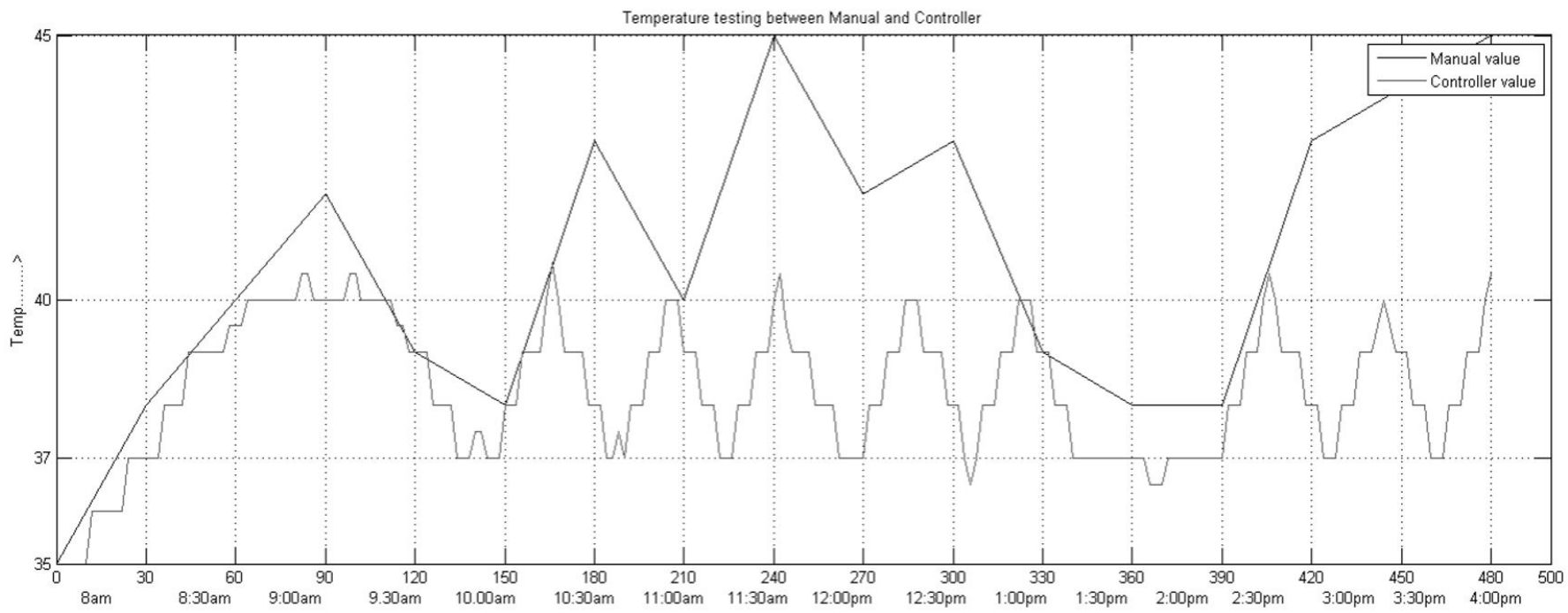

Figure 9. Time vs. Temperature (Day 4).

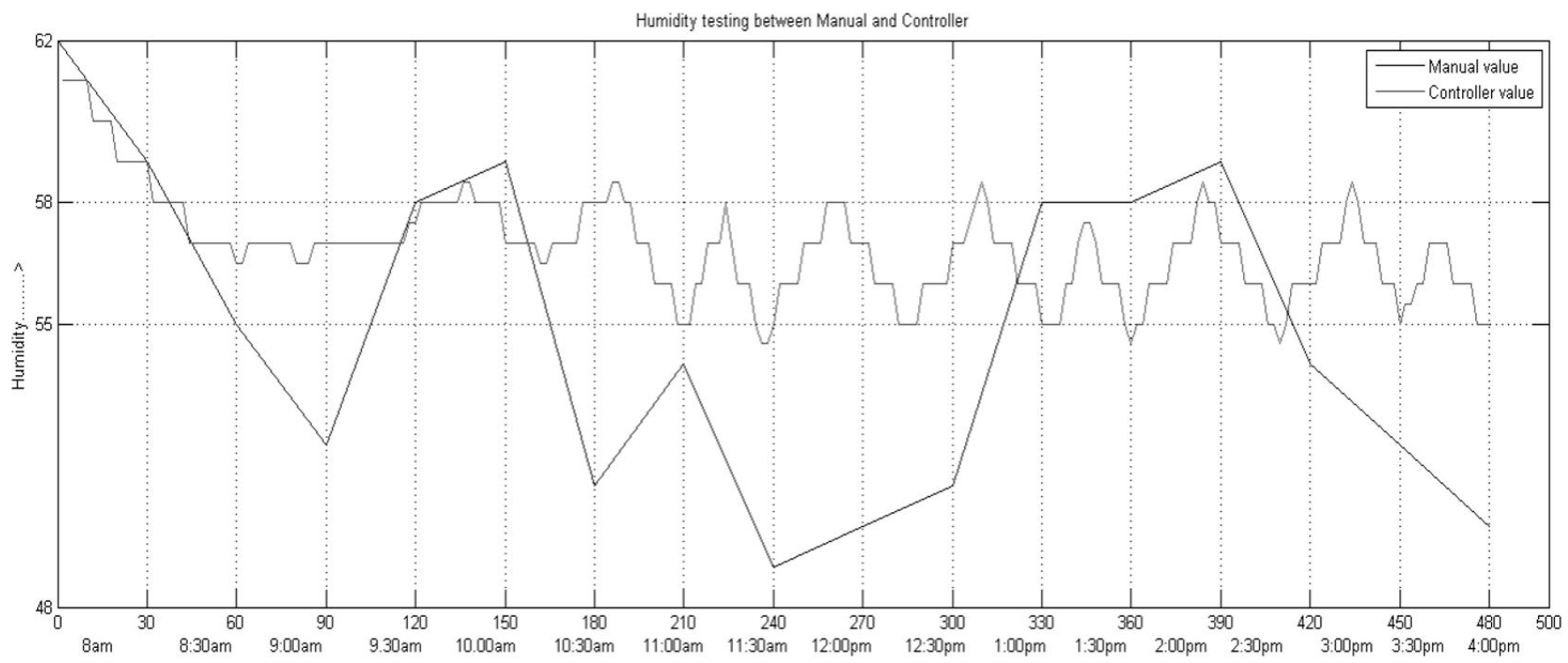

Figure 10. Time vs. Humidity (Day 4). 
Table 4. Average of Field Observation (Day 4).

\begin{tabular}{lcccc}
\hline \multicolumn{5}{c}{ Day 4 } \\
\hline \multicolumn{1}{c}{ Parameters } & Min & Max & Median & SD \\
\hline Temperature $\left({ }^{\circ} \mathrm{C}\right)$ & 35 & 45 & 40 & 5.02 \\
Humidity $(\%)$ & 50 & 61 & 55.5 & 5.02 \\
Soil Moisture (\%) & 94 & 100 & 97 & 2.38 \\
Time (hr.) & 0 & 8 & 4 & 3.53 \\
Distance (ft.) & 0 & 150 & 75 & 74.5 \\
\hline
\end{tabular}

Table 5. Average of Field Observation (Day 5).

\begin{tabular}{lcccc}
\hline \multicolumn{5}{c}{ Day 5} \\
\hline \multicolumn{1}{c}{ Parameters } & Min & Max & Median & SD \\
\hline Temperature $\left({ }^{\circ} \mathrm{C}\right)$ & 33 & 43 & 38 & 4.5 \\
Humidity $(\%)$ & 56 & 63 & 59 & 3.53 \\
Soil Moisture (\%) & 95 & 99 & 97 & 2.06 \\
Time (hr.) & 0 & 8 & 4 & 3.53 \\
Distance (ft.) & 0 & 150 & 75 & 74.5 \\
\hline
\end{tabular}

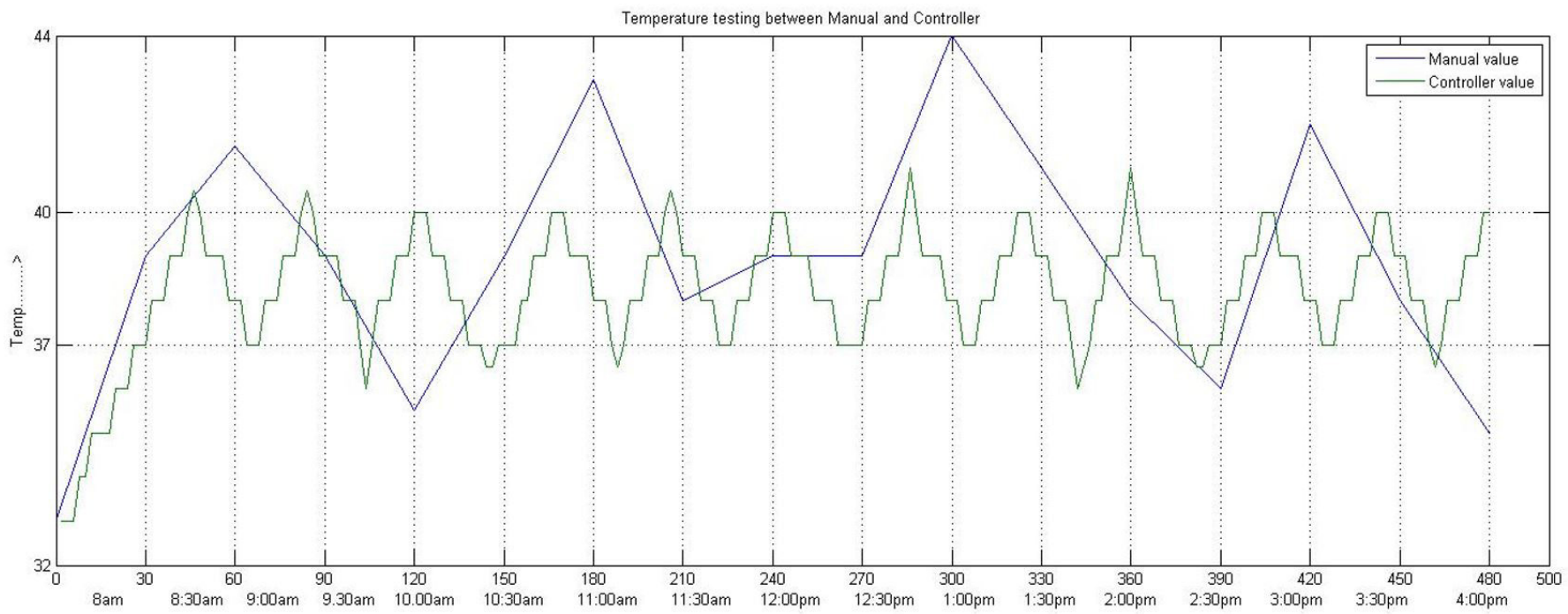

Figure 11. Time vs. Temperature (Day 5).

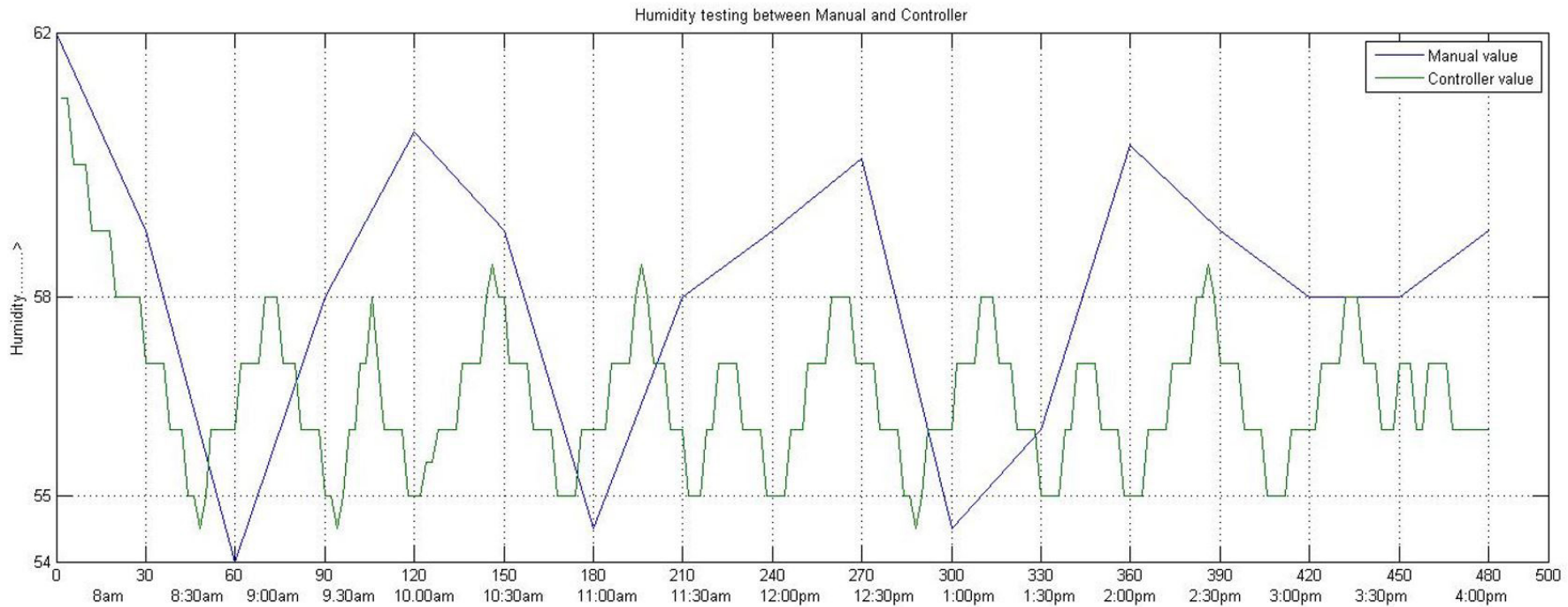

Figure 12. Time vs. Humidity (Day 5).

Table 8 summarizes the percentage time during which the environmental parameters have exceeded threshold values. It is evident that ACHPA significantly reduced the percentage variation time depicting better control. ACHPA improved 22\% of the total sampled variation time for temperature giving a $5 \mathrm{X}$ better control on temperature. Humidity variation is improved by $30 \%$ giving $6 \mathrm{X}$ better humidity control as compared to manual control. Overshoot in the temperature and humidity reduced from $7.5 \%$ to $1 \%$ giving $7 \mathrm{X}$ better control. The proposed system checks the values of parameters through sensors and regulates the actuators to maintain the threshold range, providing excellent control over environmental parameters. 


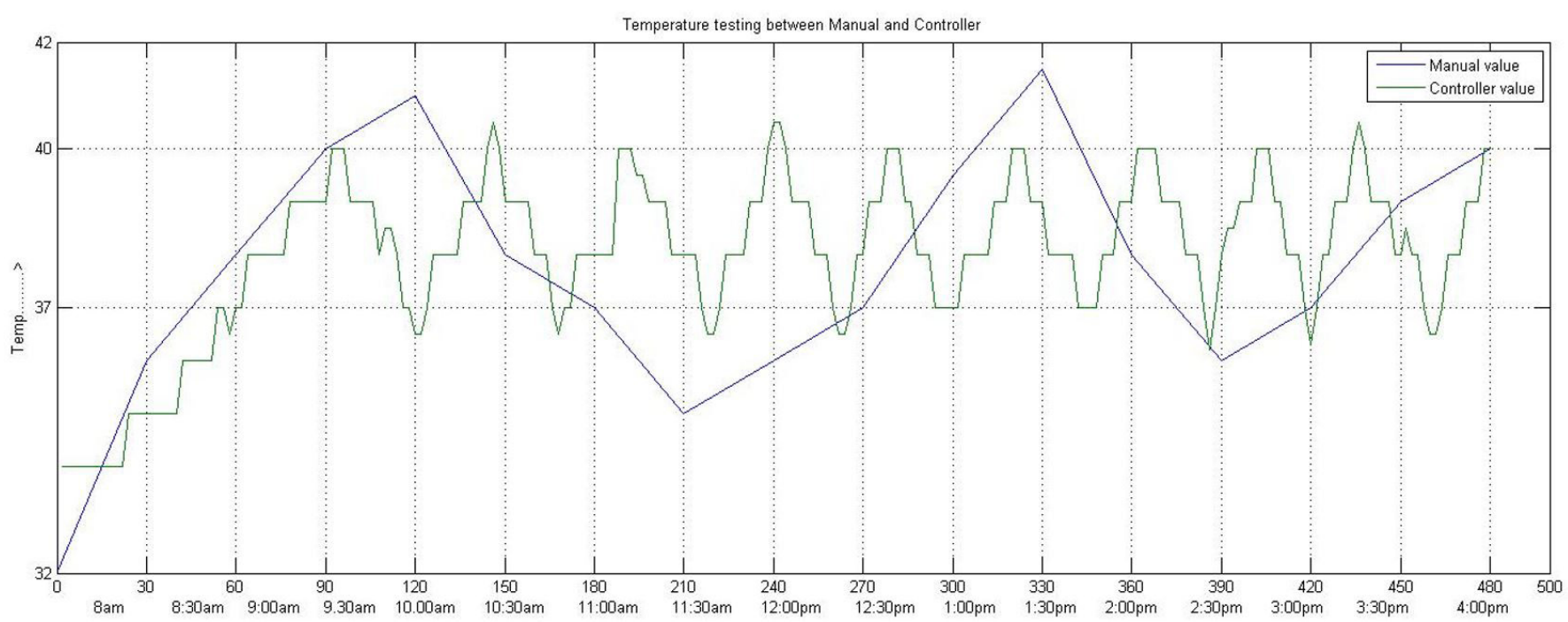

Figure 13. Time vs. Temperature (Day 6).

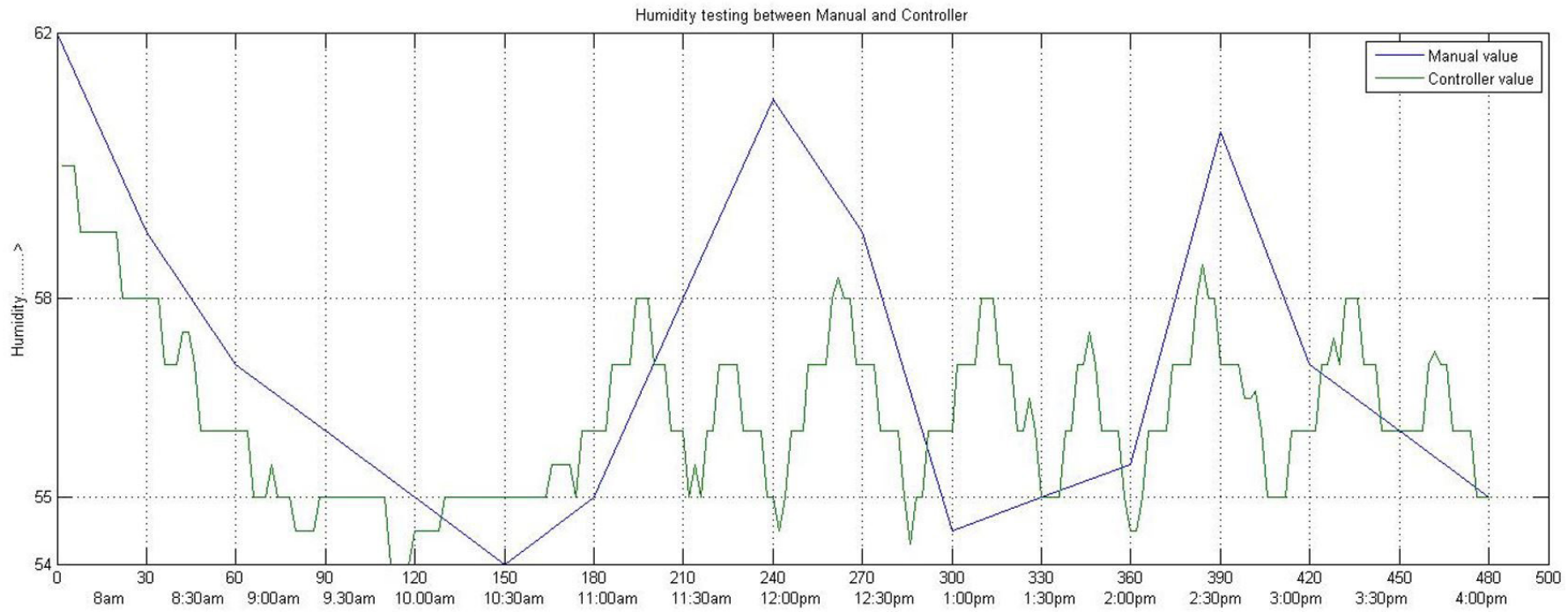

Figure 14. Time vs. Humidity (Day 6).

Table 6. Average of Field Observation (Day 6).

\begin{tabular}{lcccc}
\hline \multicolumn{1}{c}{ Parameters } & Min & Day 6 & Median & SD \\
\hline Temperature $\left({ }^{\circ} \mathrm{C}\right)$ & 32 & 41 & 37 & 4.3 \\
Humidity (\%) & 56 & 61 & 58 & 3.42 \\
Soil Moisture (\%) & 95 & 100 & 97.5 & 2.06 \\
Time (hr.) & 0 & 8 & 4 & 3.53 \\
Distance (ft.) & 0 & 150 & 75 & 74.5 \\
\hline
\end{tabular}

Table 7. Comparision between manual and controller values.

\begin{tabular}{|c|c|c|c|c|c|c|c|c|c|c|c|c|}
\hline \multirow{3}{*}{$\begin{array}{c}\text { Days/ } \\
\text { Parameters }\end{array}$} & \multicolumn{6}{|c|}{ Manual Values } & \multicolumn{6}{|c|}{ Controller Values } \\
\hline & \multicolumn{2}{|c|}{ Temp $\left({ }^{\circ} \mathrm{C}\right)$} & \multicolumn{2}{|c|}{ Humidity (\%) } & \multicolumn{2}{|c|}{ Soil Moisture (\%) } & \multicolumn{2}{|c|}{ Temp $\left({ }^{\circ} \mathrm{C}\right)$} & \multicolumn{2}{|c|}{ Humidity (\%) } & \multicolumn{2}{|c|}{ Soil Moisture (\% } \\
\hline & Min & $\operatorname{Max}$ & Min & $\operatorname{Max}$ & Min & Max & Min & $\operatorname{Max}$ & Min & $\operatorname{Max}$ & Min & $\operatorname{Max}$ \\
\hline Day 1 & 33 & 43 & 55 & 63 & 75 & 86 & 37 & 40 & 55 & 58 & 95 & 100 \\
\hline Day 2 & 30 & 35 & 55 & 63 & 51 & 78 & 30 & 35 & 55 & 58 & 95 & 100 \\
\hline Day 3 & 34 & 42 & 53 & 62 & 67 & 81 & 37 & 40 & 55 & 58 & 95 & 100 \\
\hline Day 4 & 35 & 40 & 50 & 61 & 59 & 83 & 37 & 40 & 55 & 58 & 95 & 100 \\
\hline Day 5 & 33 & 43 & 55 & 63 & 57 & 81 & 37 & 40 & 55 & 58 & 95 & 100 \\
\hline Day 6 & 32 & 41 & 56 & 61 & 64 & 89 & 37 & 40 & 55 & 58 & 95 & 100 \\
\hline
\end{tabular}


Table 8. Comparitive results of manual and automatic controlled tunnel farm.

\begin{tabular}{lccc}
\hline \multicolumn{1}{c}{ Parameter } & $\begin{array}{c}\text { Manual } \\
\text { Control }\end{array}$ & $\begin{array}{c}\text { Automatic } \\
\text { Control }\end{array}$ & $\begin{array}{c}\text { Percentage } \\
\text { Difference }\end{array}$ \\
\hline Temperature variation & $27.5 \%$ & $5.41 \%$ & $22 \%$ \\
Humidity variation & $36.2 \%$ & $5.62 \%$ & $30 \%$ \\
Overshoot & $7.5 \%$ & $1 \%$ & $6.5 \%$ \\
\hline
\end{tabular}

\section{Conclusion}

The automatic controlled system based on sensor and actuator technology is proposed, which is designed and enforced to realize modern agriculture system. Sensor module system with a controller is developed for a hydroponic system, to measure and control temperature, humidity and soil moisture.

After complete analysis of the manually and automatically controlled farm, it is concluded that the temperature variation was recorded to be $27.5 \%$ and $5.4 \%$ respectively. Hence a $5 \mathrm{X}$ better control is possible using ACHPA. The humidity variation is $36.2 \%$ and $5.6 \%$ for manually and automatically controlled farm respectively resulting in 6X better control with ACHPA. The overshoot in the values are $7.5 \%$ and $1 \%$ in manually and automatically controlled farm respectively giving $7 \mathrm{X}$ better control with ACHPA.

The sensor based module system is tested and the performance of the system was approved by the experimental results. Testing, analysis and experimental results explore that it is a good solution to overcome problems occurred by manual control. In addition, it examines a reliable solution to maintain proper climate condition for environmental parameters, which results in an increase of yield, quality, and a disease free crop production.

\section{References}

Adhau, S., Surwase, R., \& Kowdiki, K. H. (2017, March 23-25). Design of fully automated low cost hydroponic system using labview and AVR microcontroller. In IEEE Internatioanl Conference on Intelligent Techniques in Control (pp. 1-4). Srivilliputhur, India: IEEE.

Agrawal, N. \& Singhal, S. (2015, May 15-16). Smart drip irrigation system using raspberry pi and Arduino. In IEEE International Conference on Computing, Communication and Automation (ICCCA) (pp. 928-932). Noida, India: IEEE. http://dx.doi.org/10.1109/CCAA.2015.7148526.

Aniket Hade, D. M., \& Sengupta, M. (2014). Automatic control of drip irrigation system \& monitoring of soil by wireless. Journal of Agriculture and Veterinary Science, 7(4), 57-61.

Asolkar, P. S., \& Bhadade, U. S. (2015, February 26-27). An effective method of controlling the greenhouse and crop monitoring using GSM. In IEEE International Conference on Computing Communication Control and Automation (pp. 214-219). Pune, India: IEEE.

Burchi, G., Chessa, S., Gambineri, F., Kocian, A., Massa, D., Milazzo, P., Rimediotti, L., \& Ruggeri, A. (2018, May 8-9). Information Technology Controlled Greenhouse: A System Architecture. IEEE IoT Vertical and Topical Summit on Agriculture (pp. 1-6). Tuscany, Italy: IEEE.

Can, M. S., \& Ozguven, O. F. (2017). Fuzzy PID control by grouping of membership functions of fuzzy antecedent variables with neutrosophic set approach and 3-D position tracking control of a robot manipulator. Journal of Electrical Engineering and Technology, 13(2), 969-980.
Collado, E., Fossatti, A., \& Saez, Y. (2018). Smart farming: a potential solution towards a modern and sustainable agriculture in Panama. AIMS Agriculture and Food, 4(2), 266-284.

Dania, E., Wardhani, O., \& Widianto, E. D. (2015). Designing and implementing the arduino-based nutrition feedingautomation system of a prototype scaled Nutrient Film Technique (NFT) Hydroponics using Total Dissolved Solids (TDS) Sensor. 4th International Conference on Information Technology, Computer, and Electrical Engineering (ICITACEE) (pp. 170-175). Semarang, Indonesia: IEEE.

Gashgari, R., Alharbi, K., Mughrbil, K., Jan, A., \& Glolam, A. (2018, August 16-18). Comparison between Growing Plants in Hydroponic System and Soil Based System. In Proceedings of the 4th World Congress on Mechanical, Chemical, and Material Engineering. Madrid, Spain: ICMIE.

Haglund, K. J. (1988). Automatic Tuning of PID Controllers (1st ed.). Research Triangle Park, NC: Instrum. Soc. Amer.

Haglund, K. J. (1995). PID Controllers: Theory, Design and Tuning (2nd ed.). Research Triangle Park, NC: Instrum. Soc. Amer.

Hirofumi Ibayash, Y. K., Kaneda, Y., Imahara, J., Oishi, N., Kuroda, M., \& Mineno, H. (2016). A reliable wireless control system for tomato hydroponics. Sensors, 16(5), 644.

Hussain, R., Sahgal, J., \& Riyaj, M. (2013). Control of irrigation automatically by using wireless sensor network. International Journal of Soft Computing and Engineering, 3(1), 324-328.

Jahanshahi, E. s. (2015). Industrial test setup for autotuning of PID controller in large scale process: Applied to Tennessee eastman process. IFAC-Papers, 48(8), 469-476.

Jingzhuo, S. Y., Yu, L., Jingtao, H., Meiyu, X., Juwei, Z., \& Lei, Z. (2014). Novel intelligent PID control of traveling wave ultrasonic motor. ISA Transactions, 53(5), 1670-1679. http://dx.doi.org/10.1016/j. isatra.2014.05.022. PMid:24957274.

Kumar, R. R., \& Cho, J. Y. (2014). Reuse of hydroponic waste solution. Environmental Science and Pollution Research International, 21(16), 9569-9577. http://dx.doi.org/10.1007/s11356-014-3024-3. PMid:24838258.

Matos, J. C. (2002). Design of PI and PID Controllers with Transient Performance Specification. IEEE Transactions on Education, 45(4), 364-370.

Matos, J., Gonçalves, J.S. \& Torres, M.B. (2015). An automatic mechanical system for hydroponics fodder production. The Romanian Review Precision Mechanics, Optics \& Mechatronics, 47, 63-71.

Mohanraj, I. K. N. (2016). Field monitoring and automation using IOT in Agriculture Domain. Procedia Computer Science, 93, 931-939. (IEEE 6th International Conference on Advances in Computing \& Communications). http://dx.doi.org/10.1016/j.procs.2016.07.275.

Mr, B. P., \& Kulkarni, M. A. (2017). Automation of hydroponics system. IJSTE - International Journal of Science Technology \& Engineering, 3(9), 600-603.

Nalwade, R., \& Mote, T. (2017, May 11-12). Hydroponics Farming. In IEEE International Conference on Trends in Electronics and Informatics ICEI (pp. 645-650). Tirunelveli, India: IEEE.

Nishimura, T., Okuyama, Y., \& Satoh, A. (2018, October 11-14). High-accuracy and low-cost sensor module for hydroponic culture system. In 5th Global Conference on Consumer Electronics (GCCE). Kyoto, Japan: IEEE.

Niu, G., \& Masabni, J. (2018). Plant Production in Controlled Environments. Horticulturae, 4(4), 28.

Ponce, P., Molina, A., Tello, G., Ibarra, L., MacCleery, B., \& Ramirez, M. (2015, May 11-13). Experimental study for FPGA PID position controller in CNC micro-machines. In IFAC Symposium 
onInformation Control Problems in Manufacturing (pp. 2203-2207). Ottawa, Canada: IFAC.

Rammurthy, S. T. (2010). Application of topology under control wireless sensor networks in precision agriculture. In 41st Mid-Term Symposium on Taking Telecom and IT Revolution to Rural India (pp. 1-14). Telangana, India: International Institute of Information Technology Hyderabad.

Reyes, F. R., \& Rosado, A. (2005). Polynomial family PD-Type controllers for robot manipulators. Control Engineering Practice, 13(4), 441-450. http://dx.doi.org/10.1016/j.conengprac.2004.04.005.

Saha, M. K. (2017). Automated farming using microcontroller and sensors. International Journal of Scientific Research and Management Studies, 2(1), 21-30.

Sales, N., Remedios, O., \& Arsenio, A. (2015, December 14-16). Wireless Sensor and Actuator System for Smart Irrigation on the Cloud. In IEEE 2nd World Forum on Internet of Things. Milan, Italy: IEEE.

Saraswathi, D., Manibharathy, P., Gokulnath, R., Sureshkumar, E., \& Karthikeyan, K. (2018, July 6-7). Automation of Hydroponics Green House Farmingusing IOT. In International Conference on System, Computation, Automation and Networking (ICSCA) (pp. 1-4). Pondicherry, India: IEEE.

Shweta Bopshetty, M. Y. (2017). Monitoring and Controlling of Drip Irrigation using IOT with Embedded Linux Board. International Journal of Advanced Research in Computer and Communication Engineering, 6(4), 893-898. http://dx.doi.org/10.17148/IJARCCE.2017.64167.

Siddiqi, M. M. (2002). Effects of ammonium and inorganic carbon enrichment on growth and yield of a hydroponic tomato crop. Journal of Plant Nutrition and Soil Science, 165(2): 191-197.

Sihombing, P., Karina, N. A., Tarigan, J. T., \& Syarif, M. I. (2017). Automated hydroponics nutrition plants systems using arduino uno microcontroller based on android. Journal of Physics: Conference Series, 978(1):012014.

Singh, I., \& Bansal, M. (2011). Monitoring water level in agriculture using sensor networks. International Journal of Soft Computing and Engineering. 1(5), 202-204.

Sondhi, S. H., \& Hote, Y. V. (2014). Fractional order PID controller for load frequency control. Energy Conversion and Management, 85, 343-353. http://dx.doi.org/10.1016/j.enconman.2014.05.091.

Velazquez, L. A., Hernandez, M. A., Leon, M. Dominguez, R. B., \& Gutierrez, J. M. (2013, September 30-October 4). First Advances on the Development of a Hydroponic System for Cherry Tomato Culture. In IEEE 10th International Conference on Electrical Engineering, Computing Science and Automatic Control (CCE). Mexico City, Mexico: IEEE.

Ziegler, J. G., \& Nichols, N. B. (1940). Optimal settings for automatic controllers. Transactions of the ASME, 64, 759-768. 